\title{
Accounting
}

\section{Recent advances in enterprise resource planning}

\section{Sara Orougi*}

Department of Industrial Engineering, Iran University of Science and Technology, Iran

\begin{tabular}{l}
\hline C H R O N I C L E \\
\hline Article history: \\
Received June 5, 2015 \\
Received in revised format \\
August 162015 \\
Accepted November 232015 \\
Available online \\
November 252015 \\
\hline Keywords: \\
Enterprise resource planning \\
ERP \\
Success
\end{tabular}

\section{Introduction}

Enterprise resource planning (ERP) is an integrated system, which consists of various integrated applications (Deshmukh et al., 2015). ERP is implemented to collect, store, manage and interpret data from different business activities, including product planning, expenses, production and/or service delivery, sales management, inventory planning, shipping and payment (Ifinedo, 2011; Malaurent \& Avison, 2015). ERP gives a comprehensive insight of core business processes, based on common databases retained by a common database management system (Nwankpa, 2015). ERP systems normally attempt to track business resources, raw materials, production capacity, orders, purchase orders, etc. (Ifinedo et al., 2010). The ERP system is presently essential part of organizations since it gathers all organizational systems in a comprehensive system. Nevertheless, development of any ERP system varies from traditional system development (Kayser \& Tenke, 2015; Mittelstädt et al., 2015).

ERP systems may run on different computer hardware and network configurations, connecting to a database as an information repository. Therefore, we may expect such system could fail for different

\footnotetext{
* Corresponding author.

E-mail address: s_orougi@yahoo.com (S. Orouji) 
reasons. According to Ahmad and Cuenca (2013) ERP implementation is a complex and expensive, and, very often, it costs more than what expected.

\section{Literature review}

Ahmad and Cuenca (2013) performed a study to determine the interrelationships of the critical problems involved in ERP implementation for some small and medium sized enterprises (SMEs). Ahmadi et al. (2015a) developed a method to manage different interrelated activities to get ready for implementing an ERP system. The method may help an organization evaluate its ERP implementation readiness by evaluating the degree to which it could reach the interrelated readiness relevant activities based on fuzzy cognitive maps. Ahmadi et al. (2015b) explained how to measure the readiness of an organization for ERP implementation based on a mathematical model. They estimated readiness based on fuzzy cognitive maps to incorporate all the complex causal relationships between factors. Ahmadi et al. (2015c) in another assignment used fuzzy analytical hierarchy process to determine the key success for ERP implementation.

Antoniadis et al. (2015) investigated ERP systems adoption and implementation by SMEs in the region of Western Macedonia by paying more attention to the critical factors influencing on adoption of ERPs by SMEs. The factors detected were associated with the surveyed economic and organizational characteristics of the SMEs. The results showed that although SMEs could recognize the advantages and advantages gained by the application of these systems, still the business intelligence abilities of ERP systems were underutilized. Kilic et al. (2015) implemented Analytic Network Process (ANP) and Preference Ranking Organization Method for Enrichment Evaluations (PROMETHEE) to address the ERP selection problem. They used ANP to determine the weights of all criteria, and then, used them in the PROMETHEE method for optimal ranking of the alternative system choices and examined it in SMEs in İstanbul, Turkey.

According to Armstrong et al. (2015), the human brain continually creates electrical potentials representing neural communication and they can be computed at the scalp, and constitute the electroencephalogram (EEG). They used different pattern classifiers to ERPs representing the response of individuals to a stream of text designed to be familiar to various individuals. They reported that there were robustly identifiable features of the ERP, which enable labeling of ERPs. Bueno and Salmeron (2008) concentrated on decisive factors affecting on the ERP users' acceptance and implementation. They developed a technique based on the Technology Acceptance Model (TAM) for examining the effect of the Critical Success Factors (CSFs) on ERP implementation. The CSFs implemented are: "(1) top management support, (2) communication, (3) cooperation, (4) training and (5) technological complexity". Candra (2012) reported that knowledge capability that firms have can affect the success of ERP implementation. Chang et al. (1012) implemented an analytic hierarchical prediction technique to help firms become aware of the important factors influencing the ERP. Efe (2016) presented an integrated fuzzy multi criteria group decision making method for ERP system selection.

Cloud computing helps firms of Web services and rekindles the interest of providing ERP services via the Internet. It has the capabilities to reshape the way information technology (IT) services are used. Recent research have indicated that ERP delivered through SaaS will perform better than the traditional IT systems will. Chen et al. (2015) defined a CloudERP platform on which enterprise customers can choose web services and customize a unique ERP system to reach their specific requirements. The CloudERP plans to provide enterprise users with the flexibility of renting an entire ERP service through multiple vendors. Chien and Tsaur (2007) proposed a partial extension of the previous model for the success of ERP systems. The study reported that "system quality, service quality, and information quality" were most important successful factors.

Galy and Sauceda (2014) presented post-implementation practices of ERP systems and their relationship to financial performance based on econometric analysis. Grabski and Leech (2007) 
reported that groups of complementary controls have to be used in the implementation of ERP systems to reach a successful ERP implementation. Horváth (2015) reported that a better insight of auditory ERP attenuation phenomena could be reached by investigations of the kinds of actions. Hsu et al. (2015) aimed to study how various qualities of an ERP system could influence its post-implementation success from the user's perspective. In their survey, service quality was determined to substantially interact with information quality and system quality to promote an ERP system's post-implementation success by improving employees' use. Hustad and Olsen (2013) reported on a multiple case study performed in five SMEs. These firms applied ERP systems and the concentrated on the critical issues, activities and key actors across various stages of the ERP life cycle in these enterprises. SMEs had less resources and competencies about complex ERP systems compared with larger firms. Thus ERP projects proved to be risky and more expensive for SMEs.

Hwang et al. (2015) presented an ERP system implementation and empirically studied its effect of this implementation on performance outcomes. They argued that effective ERP implementation needed better front-end planning to enable timely coordination, continuous interactions and organization-wide application. They reported that an ERP implementation strategy alone had no direct impact on performance but would have an indirect impact on performance through IT-enabled combinative capabilities, implying that IT-enabled combinative capabilities could possibly mediate performance outcomes. Law and Ngai (2007) studied the relationships between the success of ERP system adoption, extent of business process improvement (BPI), and organizational performance and examined the relationships between the outcomes of these initiatives and such organizational factors as strategic intent, senior management support, and the status of the IT function within a company. Their results also explained that CEO-IT distance may have small direct bearing on the outcomes of ERP and BPI initiatives.

Lee et al. (2016) investigated the effects of organizational culture and top management support of knowledge sharing on the success of software process improvement. They reported the implication to improve our knowledge about how organizational culture and top management could possibly support drive effective knowledge sharing on the way to software process improvement success. Liu (2011) investigated the effect of critical success factors on ERP knowledge management on management performance in high-tech industries in Taiwan. McGinnis and Huang (2007) defined a four-stage ERP refinement model that included knowledge management (KM) into each major implementation phase. This knowledge-enhanced ERP application model gives insights when implemented to study ERP success.

Rajan and Baral (2015) reported that computer self-efficacy, organizational support, training, and compatibility had positive effects on ERP usage which in turn had significant effect on panoptic empowerment and individual performance. Ram et al. (2013) reported that reaching successful ERP system implementation could mediate the degree to which a critical success factors influences on output performance improvement. In the context of ERP implementation, Rosburg et al. (2014) tried to determine some evidence for an involvement of the auditory cortex when subjects try to retrieve vocalized information, and hypothesized that adopting retrieval orientation could be advantage for retrieval accuracy. Their findings were suggestive for an involvement of the auditory cortex in retrieval attempts of vocalized information and approved that adopting retrieval orientation could contribute for retrieval accuracy. Rouhani and Ravasan (2013) discussed the idea of forecasting ERP postimplementation success based on organizational profiles using the Artificial Neural Network (ANN) method to articulate the relationships between some organizational factors and ERP success. Sudhaman and Thangavel (2015) analyzed the efficiency of ERP projects based on their quality measures based on Data Envelopment Analysis model and determined the most efficient ERP projects.

Sun et al. (2015a) presented a model for critical success factor (CSF) assessment of ERP system implementation, and proposed a structured method to assist a SME to determine the key necessities and measurements that determine its achievement of ERP implementation. Based on realistic data, CSFs 
were converted into quantitative information to reflect measurements including cost, schedule, and goal achievement that must be addressed during implementation. Sun et al. (2015b) presented a step-by-step assessment and improvement technique for ERP implementation and implemented in three firms. In their implementation, they first proposed a five-stage ERP implementation model. Second, about 80 critical success factors (CSFs) from the literature were elaborated into key performance indices (KPIs), which are related to each stage of ERP implementation by ten local ERP experts. Third, the weights of the KPIs were measured using the Dumpster-Shafer method and the evaluation of ten experts. Tsai et al. (2011) presented a study on the effects of internal/external facilitators on the project success of ERP using structural equation modeling technique.

Vuillier et al. (2015) reported that a motivational situation triggers the application of a proactive strategy when low cognitive control is needed. Wang and Chen (2006) proposed a model of ERP governance to study the relationship between different governance mechanisms and their capacity to achieve project hazards. Wang and Chen (2006) and Wang et al. (2008) recommended that governance equilibrium, when treated as a multidimensional construct, could give a holistic representation of complex interfirm governance and help researchers match broad predictors with broad outcomes, leading to bigger explanatory power of governance mechanisms on ERP project success. Yoon (2009) provided strategic insights for better managing ERP systems by determining the impacts of organizational citizenship behaviors in ERP context.

\section{Discussion}

In this paper, we have presented a survey on recent advances of the implementation of various techniques to identify different factors influencing on the success of ERP implementation. The study has highlighted several factors including top management support, communication, cooperation, training and technological complexity, which were believed to be the most influential factors on development of ERP systems. In addition, several multi criteria decision making systems were used for ranking different software packages for ERP implementation. Moreover, many studies have attempted to consider mathematical methods by considering uncertainty associated with data.

\section{Acknowledgement}

The author would like to thank the anonymous referees for constructive comments on earlier version of this paper.

\section{References}

Ahmad, M. M., \& Cuenca, R. P. (2013). Critical success factors for ERP implementation in SMEs. Robotics and Computer-Integrated Manufacturing, 29(3), 104-111.

Ahmadi, S., Papageorgiou, E., Yeh, C. H., \& Martin, R. (2015a). Managing readiness-relevant activities for the organizational dimension of ERP implementation. Computers in Industry, 68, 89-104.

Ahmadi, S., Yeh, C. H., Martin, R., \& Papageorgiou, E. (2015b). Optimizing ERP readiness improvements under budgetary constraints. International Journal of Production Economics, 161, 105-115.

Ahmadi, S., Yeh, C. H., Papageorgiou, E. I., \& Martin, R. (2015c). An FCM-FAHP approach for managing readiness-relevant activities for ERP implementation. Computers \& Industrial Engineering, 88, 501-517.

Antoniadis, I., Tsiakiris, T., \& Tsopogloy, S. (2015). Business intelligence during times of crisis: Adoption and usage of ERP systems by SMEs. Procedia-Social and Behavioral Sciences, 175, 299307.

Armstrong, B. C., Ruiz-Blondet, M. V., Khalifian, N., Kurtz, K. J., Jin, Z., \& Laszlo, S. (2015). Brainprint: Assessing the uniqueness, collectability, and permanence of a novel method for ERP biometrics. Neurocomputing, 166(20), 59-67. 
Bueno, S., \& Salmeron, J. L. (2008). TAM-based success modeling in ERP. Interacting with Computers, 20(6), 515-523.

Candra, S. (2012). ERP implementation success and knowledge capability. Procedia-Social and Behavioral Sciences, 65, 141-149.

Chang, T. H., Hsu, S. C., Wang, T. C., \& Wu, C. Y. (2012). Measuring the success possibility of implementing ERP by utilizing the Incomplete Linguistic Preference Relations. Applied Soft Computing, 12(5), 1582-1591.

Chen, C. S., Liang, W. Y., \& Hsu, H. Y. (2015). A cloud computing platform for ERP applications. Applied Soft Computing, 27, 127-136.

Chien, S. W., \& Tsaur, S. M. (2007). Investigating the success of ERP systems: Case studies in three Taiwanese high-tech industries. Computers in Industry, 58(8), 783-793.

Deshmukh, P. D., Thampi, G. T., \& Kalamkar, V. R. (2015). Investigation of quality benefits of ERP implementation in Indian SMEs. Procedia Computer Science, 49, 220-228.

Efe, B. (2016). An integrated fuzzy multi criteria group decision making approach for ERP system selection. Applied Soft Computing, 38, 106-117.

Galy, E., \& Sauceda, M. J. (2014). Post-implementation practices of ERP systems and their relationship to financial performance. Information \& Management, 51(3), 310-319.

Grabski, S. V., \& Leech, S. A. (2007). Complementary controls and ERP implementation success. International Journal of Accounting Information Systems, 8(1), 17-39.

Horváth, J. (2015). Action-related auditory ERP attenuation: Paradigms and hypotheses. Brain Research, 1626, 54-65.

Hsu, P. F., Yen, H. R., \& Chung, J. C. (2015). Assessing ERP post-implementation success at the individual level: Revisiting the role of service quality. Information \& Management, 52(8), 925-942.

Hustad, E., \& Olsen, D. H. (2013). Critical issues across the ERP life cycle in small-and-medium-sized enterprises: Experiences from a multiple case study. Procedia Technology, 9, 179-188.

Hwang, D., Yang, M. G. M., \& Hong, P. (2015). Mediating effect of IT-enabled capabilities on competitive performance outcomes: An empirical investigation of ERP implementation. Journal of Engineering and Technology Management, 36, 1-23.

Ifinedo, P., Rapp, B., Ifinedo, A., \& Sundberg, K. (2010). Relationships among ERP postimplementation success constructs: An analysis at the organizational level. Computers in Human Behavior, 26(5), 1136-1148.

Ifinedo, P. (2011). Examining the influences of external expertise and in-house computer/IT knowledge on ERP system success. Journal of Systems and Software, 84(12), 2065-2078.

Kayser, J., \& Tenke, C. E. (2015). Issues and considerations for using the scalp surface Laplacian in EEG/ERP research: a tutorial review. International Journal of Psychophysiology, 97(3), 189-209.

Kilic, H. S., Zaim, S., \& Delen, D. (2015). Selecting “The Best” ERP system for SMEs using a combination of ANP and PROMETHEE methods. Expert Systems with Applications, 42(5), 23432352.

Law, C. C., \& Ngai, E. W. (2007). ERP systems adoption: An exploratory study of the organizational factors and impacts of ERP success. Information \& Management, 44(4), 418-432.

Lee, J. C., Shiue, Y. C., \& Chen, C. Y. (2016). Examining the impacts of organizational culture and top management support of knowledge sharing on the success of software process improvement. Computers in Human Behavior, 54, 462-474.

Liu, P. L. (2011). Empirical study on influence of critical success factors on ERP knowledge management on management performance in high-tech industries in Taiwan. Expert Systems with Applications, 38(8), 10696-10704.

Malaurent, J., \& Avison, D. (2015). From an apparent failure to a success story: ERP in China-Post implementation. International Journal of Information Management, 35(5), 643-646.

McGinnis, T. C., \& Huang, Z. (2007). Rethinking ERP success: A new perspective from knowledge management and continuous improvement. Information \& Management, 44(7), 626-634. 
Mittelstädt, V., Brauner, P., Blum, M., \& Ziefle, M. (2015). On the Visual Design of ERP Systems The-Role of Information Complexity, Presentation and Human Factors. Procedia Manufacturing, 3, 448-455.

Nwankpa, J. K. (2015). ERP system usage and benefit: A model of antecedents and outcomes. Computers in Human Behavior, 45, 335-344.

Rajan, C. A., \& Baral, R. (2015). Adoption of ERP system: An empirical study of factors influencing the usage of ERP and its impact on end user. IIMB Management Review, 27(2), 105-117.

Ram, J., Corkindale, D., \& Wu, M. L. (2013). Implementation critical success factors (CSFs) for ERP: Do they contribute to implementation success and post-implementation performance?. International Journal of Production Economics, 144(1), 157-174.

Ram, J., Wu, M. L., \& Tagg, R. (2014). Competitive advantage from ERP projects: Examining the role of key implementation drivers. International Journal of Project Management, 32(4), 663-675.

Rosburg, T., Johansson, M., Sprondel, V., \& Mecklinger, A. (2014). Retrieving self-vocalized information: An event-related potential (ERP) study on the effect of retrieval orientation. Brain and cognition, 92, 123-132.

Rouhani, S., \& Ravasan, A. Z. (2013). ERP success prediction: An artificial neural network approach. Scientia Iranica, 20(3), 992-1001.

Ruivo, P., Oliveira, T., \& Neto, M. (2015). Using resource-based view theory to assess the value of ERP commercial-packages in SMEs. Computers in Industry, 73, 105-116.

Sudhaman, P., \& Thangavel, C. (2015). Efficiency analysis of ERP projects - software quality perspective. International Journal of Project Management, 33(4), 961-970.

Sun, A. Y., Yazdani, A., \& Overend, J. D. (2005). Achievement assessment for enterprise resource planning (ERP) system implementations based on critical success factors (CSFs). International Journal of Production Economics, 98(2), 189-203.

Sun, D., Chan, C. C., Hu, Y., Wang, Z., \& Lee, T. M. (2015a). Neural correlates of outcome processing post dishonest choice: An fMRI and ERP study. Neuropsychologia, 68, 148-157.

Sun, H., Ni, W., \& Lam, R. (2015b). A step-by-step performance assessment and improvement method for ERP implementation: Action case studies in Chinese companies. Computers in Industry, 68, 4052.

Tsai, W. H., Shaw, M. J., Fan, Y. W., Liu, J. Y., Lee, K. C., \& Chen, H. C. (2011). An empirical investigation of the impacts of internal/external facilitators on the project success of ERP: A structural equation model. Decision Support Systems, 50(2), 480-490.

Vuillier, L., Whitebread, D., \& Szucs, D. (2015). ERP evidence of cognitive strategy change in motivational conditions with varying level of difficulty. Neuropsychologia, 70, 126-133.

Wang, E. T., \& Chen, J. H. (2006). The influence of governance equilibrium on ERP project success. Decision Support Systems, 41(4), 708-727.

Wang, E. T., Shih, S. P., Jiang, J. J., \& Klein, G. (2008). The consistency among facilitating factors and ERP implementation success: A holistic view of fit. Journal of Systems and Software, 81(9), 1609-1621.

Yoon, C. (2009). The effects of organizational citizenship behaviors on ERP system success. Computers in Human Behavior, 25(2), 421-428. 